\title{
Solution Process for Synthesizing Bioactive Nano-Mesh Layer on Ti-Based Bulk Metallic Glasses
}

\author{
Yuriko Fukushima ${ }^{1}$, Ken-ichi Katsumata ${ }^{1}$, Zhu Shengli ${ }^{2}$, Xie Guoqiang ${ }^{2}$, \\ Mitsuo Niinomi ${ }^{2}$, Kiyoshi Okada ${ }^{1}$ and Nobuhiro Matsushita ${ }^{1, *}$ \\ ${ }^{1}$ Materials and Structures Laboratory, Tokyo Institute of Technology, Yokohama 226-8503, Japan \\ ${ }^{2}$ Institute for Materials Research, Tohoku University, Sendai 980-8577, Japan
}

\begin{abstract}
Ti based Bulk Metallic Glasses (BMGs) were treated by Hydrothermal (H), Electrochemical (E) and Hydrothermal-Electrochemical (H-E) processes in $\mathrm{NaOH}$ solution and all of these processes enabled fabrication of titanate nano-mesh structures on their surfaces. XPS data suggested that the amount of cytotoxic $\mathrm{Cu}$ was drastically decreased for the samples treated by $\mathrm{H}$-E process. Specimens having nano-mesh structures on their surface were immersed in Simulated Body Fluid (SBF) for 12 days. The results of the SBF test supported the fact that nano-mesh structures fabricated by these three methods have bioactivity. However, only the specimen treated by H-E process exhibited very good adhesion performance between the induced hydroxyapatite layer and substrate with intermediated titanate nanomesh layer. These results indicated that the $\mathrm{H}$-E process was the best among three to fabricate a low cytotoxic bioactive nano-mesh layer on Ti-based BMG which enabled to induce hydroxyapatite layer with strong adhesion. [doi:10.2320/matertrans.MF201312]
\end{abstract}

(Received January 31, 2013; Accepted March 19, 2013; Published April 26, 2013)

Keywords: biomaterial, nanostructure, bulk metallic glasses, titanium alloy, hydroxyapatite

\section{Introduction}

Bulk Metallic Glasses (BMGs) have been attracting a lot of attention as novel metallic materials for more than 10 years due to their excellent mechanical properties for implants such as high strength, large elastic strain and low Young's modulus. ${ }^{1-5)}$

Especially a series of Ti-based BMG $\left(\mathrm{Ti}_{40} \mathrm{Zr}_{10} \mathrm{Cu}_{36} \mathrm{Pd}_{14}\right)$ having high corrosion resistance are recognized as biomedical materials suitable for dental application. ${ }^{6,7)}$ However, despite of favorable mechanical properties, the BMG cannot be joined directly to human bone due to their relative high chemical stability. Therefore, it is essential to attain biocompatibility (such as bone inducing ability) of the BMG by means of ceramic coating on its surface. In addition, for practical applications, the surface modification which enables the fabrication of bioceramic layer having less or no $\mathrm{Cu}$ elements would be required. ${ }^{8)}$ Recently, the formation of bioactive titanate layer on $\mathrm{Ti}_{40} \mathrm{Zr}_{10} \mathrm{Cu}_{36} \mathrm{Pd}_{14}$ by Hydrothermal-Electrochemical process was reported. ${ }^{9}$ (This technique has the advantage of a processing temperature typically less than $423 \mathrm{~K}$, which is low enough to avoid crystallization of Ti-based BMG.

In the present study, the bioactive surface modification on Ti-based BMG surface was investigated by comparing Hydrothermal-Electrochemical (H-E) process with conventional Hydrothermal $(\mathrm{H})$ and Electrochemical (E) one, respectively.

\section{Experiments - Specimen preparation and measurement -}

The Ti-based BMG specimens $(4.0 \times 1.0 \mathrm{~cm}$ in size $)$ were degreased prior to the start of the experiment. The degreasing was carried out by sonication in acetone for $10 \mathrm{~min}$, rinsing with distilled water (Millipore Milli-Q), and then drying at

*Corresponding author, E-mail: matsushita@msl.titech.ac.jp

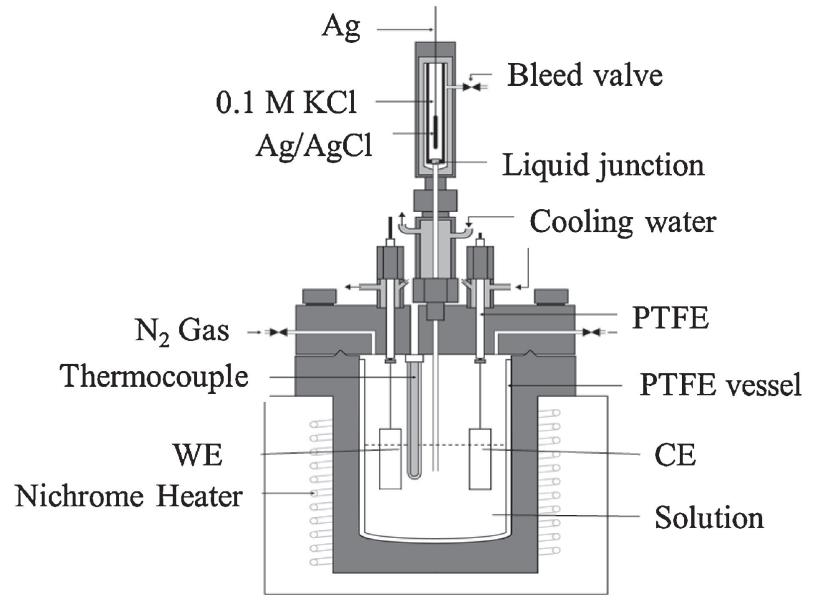

Fig. 1 Schematic illustration of the experimental equipment for the hydrothermal-electrochemical apparatus.

ambient temperature. BMG substrate and a platinum plate suspended in $\mathrm{NaOH}$ solution were used as working and counter electrodes, respectively as show in Fig. 1. The distance between the electrodes was maintained at $6 \mathrm{~cm}$. The active anodic surface area immersed in the electrolyte was $3 \mathrm{~cm}^{2}$. The BMG substrates were treated with an aqueous solution of $0.2-5.0 \mathrm{M}$ of $\mathrm{NaOH}$ solution as the electrolyte, at $90-150^{\circ} \mathrm{C}$ for $2 \mathrm{~h}$, using each $\mathrm{H}, \mathrm{E}$ or $\mathrm{H}-\mathrm{E}$ processes. A constant electric current of $5.0 \mathrm{~mA} \cdot \mathrm{cm}^{-2}$ was applied between the electrodes during the $\mathrm{E}$ and $\mathrm{H}-\mathrm{E}$ process. After each treatment, the specimens were washed with distilled water to remove the alkali, and finally dried at $60^{\circ} \mathrm{C}$ for $24 \mathrm{~h}$ in air.

The surface morphology was observed by scanning electron microscopy (SEM). The SEM images of the specimens were taken by a Hitachi SP 4500 microscope operating at $15 \mathrm{kV}$. The sample surface was analyzed by Raman spectroscopy, using a T64000 Jobin-Yvon spectrometer with 

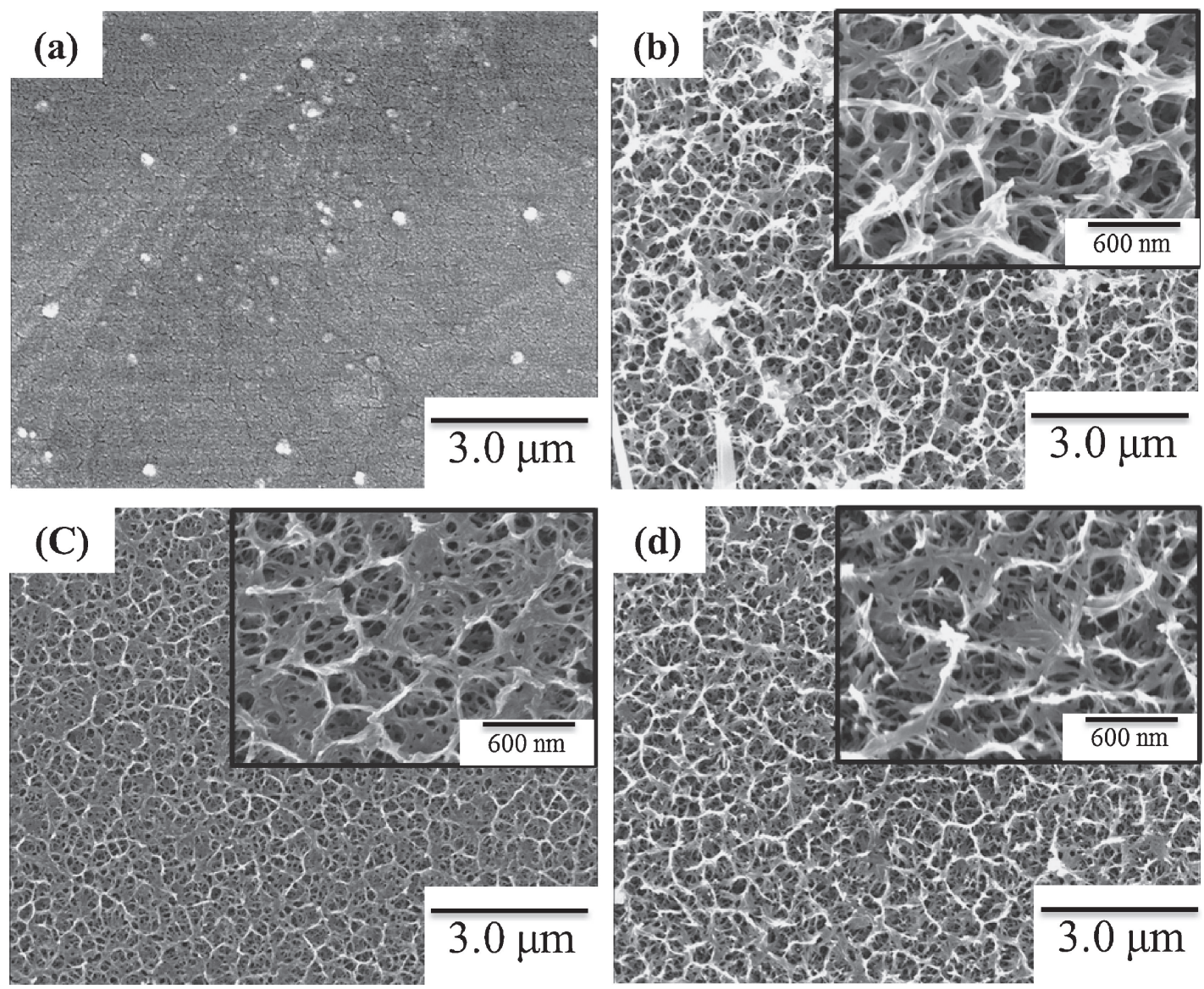

Fig. 2 Surface SEM micrographs of (a) raw substrate, obtained after treatment of (b) H, (c) E and (d) H-E process.

an argon laser $(514.5 \mathrm{~nm})$ operated at $50 \mathrm{~mW}$. The elemental composition of the titanate nano-mesh layer was characterized by X-ray photoelectron spectroscopy (XPS). In order to evaluate the biocompatibility of the surface layer, in vitro test were performed on the treated specimens, which were soaked in Simulated Body Fluid (SBF) with ion concentration nearly equal to those of human blood plasma at $36.5^{\circ} \mathrm{C}$ for 12 days. The SBF was prepared according to the recipes reported by Kokubo et al. ${ }^{10,11)}$

\section{Results and Discussions}

Figure 2 shows the SEM micrographs of (a) raw material, treated by (b) $\mathrm{H}$, (c) $\mathrm{E}$ and (d) $\mathrm{H}$-E process in $5 \mathrm{M} \mathrm{NaOH}$ solution. Nanowire arrays have been uniformly formed on a large scale on the substrate. We named these nanowire arrays as "nano-mesh layer", with diameters of tens of nanometers. It is interesting to note the similarities in the morphologies of these samples. This result suggested that all of these processes enabled to fabricate nano-mesh layers on the surface of Ti based BMG.

The crystalline phases of the nano-mesh materials were examined using X-ray diffractometer. Figure 3 shows X-ray diffraction patterns for the bare $\mathrm{BMG}$, treated by $\mathrm{H}, \mathrm{E}$ and $\mathrm{H}-\mathrm{E}$ process, respectively, in $5.0 \mathrm{M}$ of $\mathrm{NaOH}$ solution for $2 \mathrm{~h}$. From this figure, only the broad diffraction peak of the substrate at $2 \theta=42$ degree was observed. No sharp peak corresponding to a crystalline phase could be detected. This

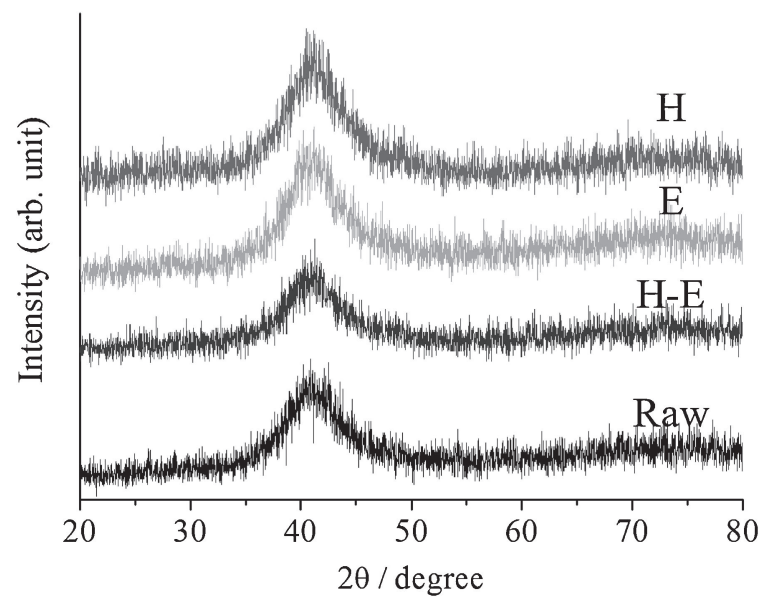

Fig. $3 \mathrm{X}$-ray diffraction patterns for $\mathrm{Ti}_{40} \mathrm{Zr}_{10} \mathrm{Cu}_{36} \mathrm{Pd}_{14}$.

result suggested that the nano-mesh materials maintained its amorphous structure after the treatment.

The composition of these nano-mesh layers was characterized using Raman spectroscopy and XPS. Figure 4 shows Raman spectra of the treated samples. Obvious peaks were observed only for $\mathrm{H}-\mathrm{E}$ process. Unlike the other two methods, the H-E process may promote the formation of nano-mesh layer and thus specific peak was obtained in this case. The peak obtained around $300 \mathrm{~cm}^{-1}$ is similar to that of titanate nanowires, which was reported by Zerate et al. and 
Gao et al. ${ }^{12,13)}$ These results indicate that nano-mesh layer prepared by $\mathrm{H}-\mathrm{E}$ process has a sodium-containing titanate phase.

The XPS results are compiled in Table 1. XPS analysis demonstrated that nano-mesh layer has a large amount of $\mathrm{Ti}$, $\mathrm{O}_{2}$ and $\mathrm{Na}$. Therefore, the presence of sodium titanate in the nano-mesh layer is supported by these findings. The study revealed significant differences in chemical composition

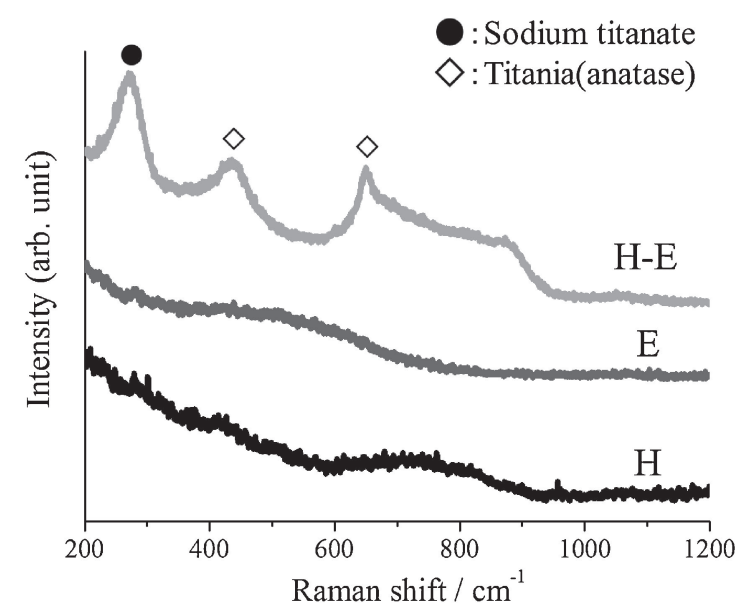

Fig. 4 Raman spectra of treated samples surface.

Table 1 Results of chemical composition of upmost surface of treated sample.

\begin{tabular}{ccccccc}
\hline at\% & $\mathrm{O}$ & $\mathrm{Ti}$ & $\mathrm{Na}$ & $\mathrm{Zr}$ & $\mathrm{Cu}$ & $\mathrm{Pd}$ \\
\hline $\mathrm{H}$ & 68 & 18 & 5.1 & 0.72 & $\mathbf{8 . 2}$ & - \\
$\mathrm{E}$ & 72 & 21 & 2.3 & 0.32 & $\mathbf{3 . 9}$ & - \\
$\mathrm{H}-\mathrm{E}$ & 79 & 18 & 2.6 & 0.56 & $\mathbf{0 . 4 9}$ & - \\
\hline
\end{tabular}

among treated samples. The concentration of $\mathrm{Cu}$, an element known for its cytotoxicity, was drastically decreased in the case of H-E samples. This phenomenon could be explained by the formation mechanism as described below. According to the potential-pH diagrams of pure $\mathrm{Ti}, \mathrm{Zr}$ and $\mathrm{Cu}$, they are dissolved in the alkaline solution in the form of anions such as $\mathrm{HTiO}^{-}, \mathrm{HZrO}^{-}$and $\mathrm{CuO}_{2}{ }^{2-}{ }^{14)}$ Only the $\mathrm{HTiO}^{-}$can form insoluble sodium titanate by reacting with $\mathrm{Na}^{+}$, followed by the precipitation on the surface of the alloy. In the case of $\mathrm{H}$ and $\mathrm{E}$ treatment, respectively, the formation rate was slower than that of $\mathrm{H}-\mathrm{E}$ method. Therefore the dissolved $\mathrm{Cu}$ ions existing in the vicinity of the surface were incorporated into the surface layer. This mechanism indicates that the combination of $\mathrm{H}$ and $\mathrm{E}$ process could fabricate low $\mathrm{Cu}$ cytotoxicity bioactive nano-mesh layer.

Finally, the bioactivity of the surface-modified $\mathrm{Ti}_{40} \mathrm{Zr}_{10^{-}}$ $\mathrm{Cu}_{36} \mathrm{Pd}_{14}$ nano-mesh layer was tested by immersing it into the SBF. Figure 5 shows SEM images of treated samples of (a) H, (b) E and (c) H-E process after being immersed for 12 days in SBF. After the test, hydroxyapatite formation in the network surface was confirmed (Fig. 2). By means of Energy Dispersive X-ray Spectroscopy, the $\mathrm{Ca} / \mathrm{P}$ ratio was identified to be approximately 1.72 . This value is nearly equal to the stoichiometric composition of hydroxyapatite. The above results suggested that the nano-mesh layers fabricated by any of the three methods have bioactivity. However, hydroxyapatite layers produced by $\mathrm{H}$ and $\mathrm{E}$ process, respectively, were peeled off after drying. On the contrast, the layer synthesized by H-E process have high adhesion strength as seen in Fig. 6. This can be explained by the presence of interfacial surface between the hydroxiapatite and substrate. Figure 7 shows the cross section view after (a) H, (b) E and (c) H-E process, respectively. In the cross section of the sample treated by only $\mathrm{H}$ or $\mathrm{E}$ process
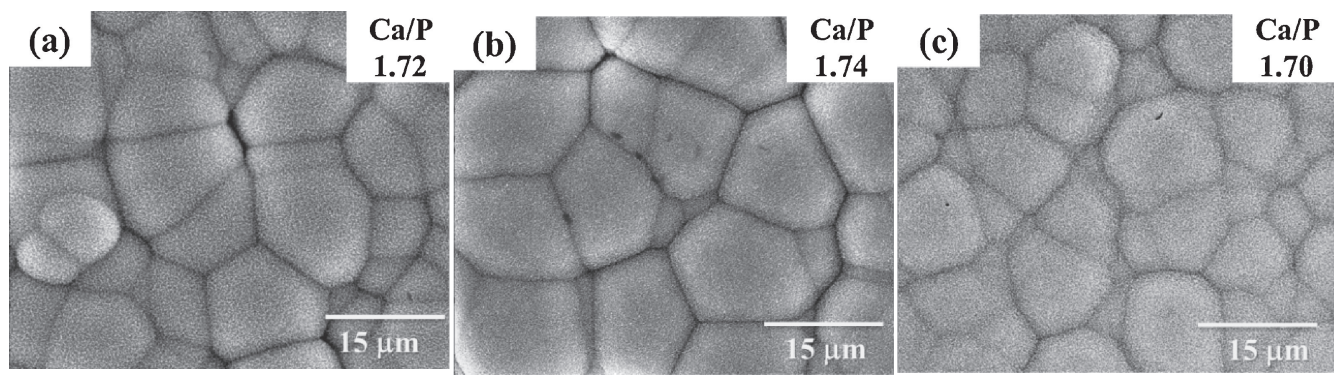

Fig. 5 Surface SEM images of samples treated by (a) H, (b) E and (c) H-E process after SBF immersion for 12 days.

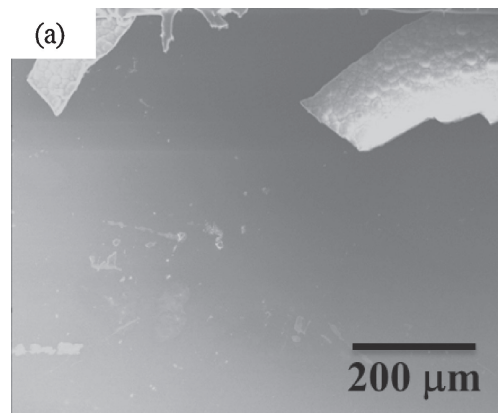

(b)

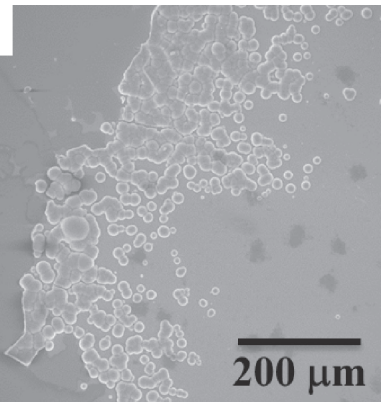

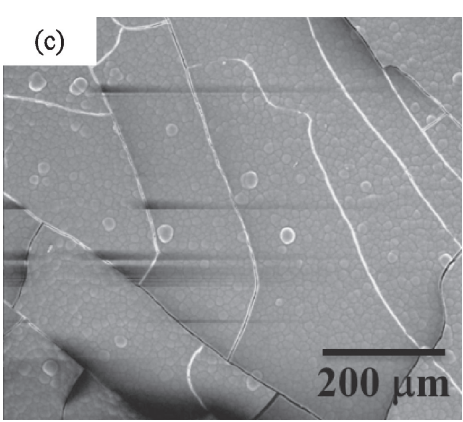

Fig. 6 SEM images of the samples prepared by (a) H, (b) E and (c) H-E, respectively. The images shows both film surface with HAp and peeled off areas. 
(a)

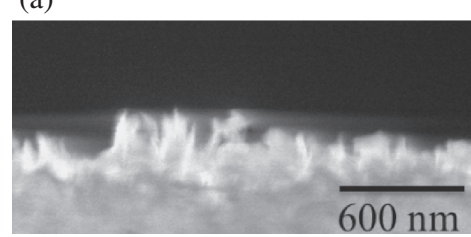

(b)

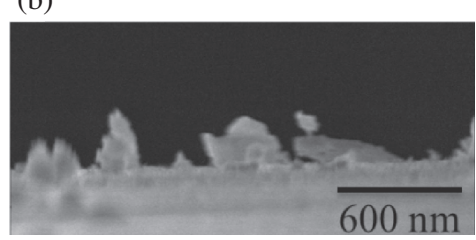

(c)

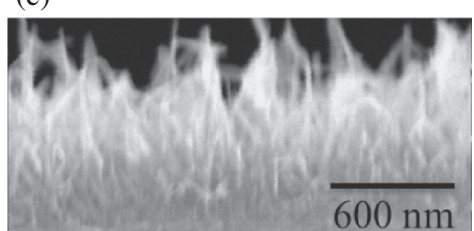

Fig. 7 Cross sectional view after sample treatment by (a) H, (b) E and (c) H-E processes.

the boundary faces were obvious. On the other hand, no boundary was observed between nanomesh layer and the BMG in the case of $\mathrm{H}-\mathrm{E}$ sample with intermediated layer whose structure was gradually changed to thickness direction. This "intermediate layer" with a widely diffused interface worked to exhibit strong adhesion of hydroxyapatite layer. The H-E process allowed the formation of this unique structure, which Yoshimura et al. named as "growing integration layer(GIL)". ${ }^{15)}$ This result indicated that H-E process improved the adhesion performance at the interface between ceramics and metallic materials.

\section{Conclusions}

Amorphous sodium titanate nano-mesh layer was formed by the $\mathrm{H}, \mathrm{E}$ and $\mathrm{H}-\mathrm{E}$ processes, respectively. The spontaneous formation of hydroxyapatite in SBF was observed in all of the samples prepared by these processes. This is indicating that the bioactive nature of the surface-modified BMG and apatite-forming ability may potentially be used for the orthopedic applications. The H-E process leaded to a relative low $\mathrm{Cu}$ concentration on the surface and also to a strong adhesion of apatite layer due to their growing integration structure. The most important point is that surface modification produced low cytotoxic $\mathrm{Cu}$ components and high adhesion strength using the $\mathrm{H}-\mathrm{E}$ process. In this work the differences between the $\mathrm{H}, \mathrm{E}$ and the combination of $\mathrm{H}$ and $\mathrm{E}$ process were pointed out, the latter was proved to be the most appropriate for actual biomedical applications.

\section{Acknowledgments}

This research was financially supported by the MEXT project of the Six Research Institute Program of Advanced Materials Development and Integration of Novel Structured
Metallic and Inorganic Materials. The authors thank Professor Yoshimura Masahiro of National Cheng Kung University, Sayaka Maruyama-graduate student of Tokyo Institute of Technology, and Jyunko Hieda of Tohoku University for their constructive suggestions.

\section{REFERENCES}

1) A. Inoue, N. Nishiyama, K. Amiya, T. Zhang and T. Masumoto: Mater. Lett. 19 (1994) 131-135.

2) K. Amiya, N. Nishiyama, A. Inoue and T. Masumoto: Mater. Sci. Eng. A 179-180 (1994) 692-696.

3) J. M. Park, Y. C. Kim, W. T. Kim and D. H. Kim: Mater. Trans 45 (2004) 595-598.

4) W. H. Wang, C. Dong and C. H. Shek: Mater. Sci. Eng. R 44 (2004) 45-89.

5) M. Z. Ma, R. P. Liu, Y. Xiao, D. C. Lou, L. Liu, Q. Wang and W. K. Wang: Mater. Sci. Eng. A 386 (2004) 326-330.

6) S. L. Zhu, X. M. Wang, F. X. Qin, M. Yoshimura and A. Inoue: Mater. Trans. 48 (2007) 2445-2448.

7) M. L. Morrison, R. A. Buchanan, A. Peker, P. K. Liaw and J. A. Horton: J. Non-Cryst. Solids 353 (2007) 2115-2124.

8) S. Buzzi, K. Jin, P. J. Uggowitzer, S. Tosatti, I. Gerber and J. F. Löffler: Intermetallics 14 (2006) 729-734.

9) N. Sugiyama, H. Y. Xu, T. Onoki, Y. Hoshikawa, T. Watanabe, N. Matsushita, X. M. Wang, F. X. Qin, M. Fukuhara, M. Tsukamoto, N. Abe, Y. Komizo, A. Inoue and M. Yoshimura: Acta Biomater. 5 (2009) 1367-1373.

10) T. Kokubo, H. M. Kim and M. Kawashita: Biomaterials 24 (2003) 2161-2175

11) T. Kokubo, H. M. Kim and M. Kawashita: Biomaterials 27 (2006) 2907-2915.

12) R. A. Zárate, S. Fuentes, J. P. Wiff, V. M. Fuenzalida and A. L. Cabrera: J Phys. Chem. Solid 68 (2007) 628-637.

13) X. Gao, H. Zhu, G. Pan, S. Ye, Y. Lan, F. Wu and D. Song: J. Phys. Chem. 108 (2004) 2868-2872.

14) M. Pouraix: Atlas of Electrochemical Equilibria in Aqueous Solutions, (Cebelcor, Houston, 1974) pp. 215-391.

15) M. Yoshimura, T. Onoki, M. Fukuhara, X. M. Wang, K. Nakata and T. Kuroda: Mater. Sci. Eng 148 (2008) 2-6. 